\title{
Imagem da Lisboa pós-colonial em Memória de Elefante de António Lobo Antunes
}

\section{Image of postcolonial Lisbon in Elephant's Memory by António Lobo Antunes}

Silvie Špánková [8346@mail.muni.cz]
Masarykova univerzita, República Checa

\section{RESUMO:}

O artigo tem por objetivo detetar as imagens urbanas presentes no romance Memória de Elefante (1979) de António Lobo Antunes. Propomos uma análise baseada em dois modos de representação que poderiam ser definidos como uma "cidade real" (imagens da cidade "visível", situada na época pós-colonial) e uma "cidade imaginária" (imagens da cidade que é lida como um cruzamento de mitos e de vários tipos de discurso). A “cidade real", para além de se referir a alguns lugares existentes em Lisboa, contém um elemento especial - o hospital psiquiátrico - que pode ser percebido como uma heterotopia (pós-colonial). Por outro lado, a "cidade imaginária", relacionada com a passagem noturna pelo espaço urbano - a demanda simbólica do eu e do Outro, revela as imagens míticas e cruzamentos textuais que enriquecem o imaginário pós-colonial da capital portuguesa.

\section{Palavras-chave:}

António Lobo Antunes; imaginário urbano; heterotopias

\begin{abstract}
:
The article focuses on urban images depicted in the novel Elephant's Memory (1979) by António Lobo Antunes. We propose an analysis based on two representational modes which can be defined as "real city" (images of "visible" city, situated in the postcolonial era) and "imaginary city" (images of city, read as a patchwork of myths and various types of discourse). The "real city", besides referring to some existing places in Lisbon, contains a spatial item - a psychiatric hospital - that could be perceived as a (postcolonial) heterotopy. The "imaginary city", connected to the night passage through the city - a symbolic demand for the self and the Other -, reveals some mythical images and textual crossing that enrich the postcolonial imaginary of the Portuguese capital.
\end{abstract}

\section{KEYWORDS:}

António Lobo Antunes; urban images; heterotopias 
Mostro-te o mosto mortal da cidade. O teu corpo perde-se no pontão metálico do cais e eu, de joelhos, volto o rosto para o branco sono das águas. Nuno Júdice: Poema com indicação de lugar

\begin{abstract}
E faltam-me os mares e os rios, a cábula de navegar, o astrolábio e a bússola, o porto e o desejo de aventura, a preclara ousadia de peregrinar em torno do mundo, ó coitado, manhoso, fingido e suspeitado Fernão Mendes Pinto da minha alma...
\end{abstract}

João de Melo: O Homem Suspenso

No que diz respeito aos estudos do tema urbano na obra desse ilustre escritor que é Lobo Antunes, é imprescindível referir os trabalhos pioneiros de Eunice Cabral (sobretudo o verbete "Lisboa" no Dicionário da Obra de António Lobo Antunes) como uma fonte de inspiração (Cabral 2008). Com exceção dos seus trabalhos, porém, a problemática do urbano na obra antuniana continua praticamente inexplorada. O que constitui um paradoxo, pois trata-se de uma das linhas temáticas mais fortes que exigiriam um trabalho interpretativo dedicado e paciente.

Num ensaio sobre a Lisboa de Eça de Queirós, Carlos Reis faz uma breve explanação sobre métodos de estudo do espaço, de preferência urbano, na literatura. De acordo com a sua aceção, é possível seguir, numa obra literária, três tipos de abordagem da cidade: 1. roteiro, que se fixa nos aspetos materiais de um ponto de vista descritivo, 2. relação biografista entre o escritor e a sua obra, que deteta os sítios em que o autor viveu para explicar a ficção, 3. análise da paisagem urbana e humana, que leva em consideração os procedimentos de figuração, filtros de perspetivação, dispositivos de enunciação narrativa e outros recursos narratológicos e temáti$\cos$ (Reis 2012). Naturalmente, Carlos Reis opta pela terceira linha de abordagem, a qual reitero, aprofundando-a pelo pensamento mitocrítico na sua vertente semântico-pragmática.

Os romances antunianos, em geral, exibem sempre a dimensão psicológica relacionada com as rupturas sociopolíticas em Portugal. Podemos dizer, por extensão, que esta dimensão interior é também sempre ligada ao espaço envolvente. $\mathrm{O}$ subconsciente das personagens (ou instâncias narrativas) funde-se ao espaço através de várias associações e lembranças que surgem ao acaso e aleatoriamente. Tal situação estabelece, por consequente, as duas vertentes no tratamento do espaço urbano: a vertente do físico (domínio do visível) e a vertente do mental (domínio do invisível). É precisamente no romance Memória de Elefante (1979) que este processo se revela com uma evidência indiscutível: o personagem-narrador, o psiquiatra há alguns anos regressado da guerra em Angola e há cinco meses divorciado, deambula pela cidade real (Lisboa em seus aspetos concretos, materializados), sendo esta errância acompanhada de uma viagem onírica, moldada pelas sensações, obsessões, desejos, associações e lembranças. Por outras palavras, assistimos aqui ao cruzamento de duas linhas espaciais: a horizontal/sintagmática (desvelamento cronológico dos lugares durante a viagem, imagens do real) e vertical/paradigmática (revelação dos lugares outros, imaginados ou deslocados espacial e temporalmente). Passemos em seguida à deteção das imagens urbanas relativas a estas duas vertentes que chamarei cidade real e cidade imaginária, em Memória de Elefante. 


\section{Cidade real}

No seu percurso pela cidade de Lisboa, várias vezes denominada, o protagonista passa por determinados sítios, nomeados no texto, que facilitariam a elaboração de um itinerário, se este fosse o meu propósito. Trata-se de lugares como o Martim Moniz, a avenida Almirante Reis, a Praça da Figueira, a rua do Ouro, Cais do Sodré, o Jardim das Amoreiras, avenida da República, avenida Óscar Monteiro Torres, rua Augusto Gil, Praça José Fontana, Duque de Loulé, a Marginal, Estoril etc. Convém mencionar, no entanto, que alguns lugares funcionam aqui como lugares-charneira, quer dizer como lugares que, existindo realmente em Lisboa, revelam uma carga simbólica que lhes aprofunda o significado. A estes pertenceria p. ex. a Baixa e o Tejo com a sua carga mítico-literária ou o Estoril como símbolo do luxo. Juntem-se a estes os emblemas urbanos referidos no texto, como são as estátuas ou monumentos (p. ex. estátua de D. João IV ou o busto de Cesário Verde).

Há de referir também os espaços em forma dos topoi que não surgem nomeados, mas que se filiam na mitologia urbana. Trata-se, em primeiro lugar, do Hospital, embora se saiba, a partir do macrotexto antuniano e da biografia do autor que este corresponde ao Hospital Psiquiátrico Miguel Bombarda. Pelas suas (parcas) descrições, o Hospital é demarcado como um lugar de alienação, miséria e solidão absoluta ("O Hospital em que trabalhava era o mesmo a que muitas vezes na infância acompanhara o pai: antigo convento de relógio de junta de freguesia na fachada, pátio de plátanos oxidados, doentes de uniforme vagabundeando ao acaso tontos de calmantes", p. 13). O motivo dos plátanos oxidados introduz também a seguinte isotopia da corrosão e degradação, desenvolvida através do motivo da sala de consultas:

A sala de consultas compunha-se de um armário em ruína roubado ao sótão de um ferro-velho desiludido, de dois ou três maples precários com o forro a surgir dos rasgões dos assentos como cabelos por buracos de boina, de uma marquesa contemporânea da época heróica e tísica do dr. Sousa Martins, e de uma secretária que abrigava na cavidade destinada às pernas um cesto de papéis enorme, parturiente carunchosa afligida por um feto excessivo. (p. 18, sublinhado meu)

O caduco e deteriorado, de facto, instituem no texto antuniano a imagética que se estende à perspetivação de toda a cidade, a metonímia do país pós-colonial.

O motivo do hospital pode ser considerado também uma heterotopia, no sentido sugerido por M. Foucault. Na sua conceção, a heterotopia corresponde a um espaço dentro ou fora da sociedade onde as regras e convenções sociais podem ser permanente ou temporariamente suspensas. Pode tratar-se também de um espaço de crise ou isolamento, ou de justaposição dos espaços incompatíveis entre si num sítio real. O quotidiano na heterotopia pode criar uma ilusão, um reflexo deformado da sociedade, ou então, pode atingir contornos de uma experiência surreal, na qual dominam as emoções ou ideias irracionais (Foucault 2003). Na verdade, o próprio Foucault se refere aos hospitais psiquiátricos como a um tipo evidente de heterotopia. Neste aspeto reina um consenso que não se presta à qualquer problematização. O que, porém, me parece interessante é a frequência desta imagem heterotópica dentro da obra antuniana e, com algumas modificações, também no contexto da literatura portuguesa contemporânea relativa à questão da descolonização. 
No caso de Lobo Antunes, a heterotopia do hospital aparece em Memória de Elefante como uma imagem fundatória, sendo depois desenvolvida em O Conhecimento do Inferno (1980), As Naus (1988) e A Comissão das Lágrimas (2011). Apesar de a heterotopia do hospital se vincular em todos os romances antunianos à pós-colonialidade, sincretizando-se a alienação dos doentes com a alienação das personagens, desenraizadas identitariamente, traumatizadas e desorientadas num mundo à deriva, é especialmemte nos dois últimos romances referidos que esta problemática aflora com maior urgência. Em As Naus, as pessoas que tinham abandonado as ex-colónias, juntamente com as ilustres figuras simbólicas do passado glorioso português, são acolhidas num antigo sanatório de tuberculosos, ficando à eterna espera impossível de um D. Sebastião. Neste mesmo romance figura também o hospital psiquiátrico como o espaço de última estadia de um patético D. Manuel na companhia de um Vasco da Gama. Por outro lado, em A Comissão das Lágrimas seguimos as peripécias de uma família que, comprometida com o novo regime implantado na Angola pós-colonial, prefere depois emigrar para Portugal. A protagonista Cristina, de mãe portuguesa e pai angolano, que também se assume como instância narrativa, num constante flutuar entre os vários níveis ficcionais do texto, é após o "retorno" a Portugal (que para ela não é retorno, já que nasceu em Angola), instalada numa clínica devido à sua completa alienação e incomunicabilidade.

No romance As Naus, a imagem heterotópica do hospital é ainda alterada com uma pensão em que são alojados os retornados em Lisboa. Também neste caso, como nos anteriores, o espaço surge desligado da lógica aceite e descrito pelos atributos de crise e clausura, no qual os hóspedes são submetidos a uma exploração material e mental. Semelhantemente, o topos do hotel que preserva parcialmente os atributos do hospital (psiquiátrico) aparece também no romance $O$ Retorno $(2011)^{1}$ de Dulce Maria Cardoso ou no romance A Costa dos Murmúrios (1988)² de Lídia Jorge. Em princípio, o espaço do hospital/hotel tratado nestes romances representa a metonímia do país sufocado pelos remorsos e pela perda e, em liguagem figurada, corresponde a um inferno dantesco cujos círculos concêntricos estrangulam os traidores de si mesmos e da sua aventura marítima, agora já destituída de grandeza e remetida aos filões do puro imaginário:

Possível aqui e lá fora que os muros do hospital são concêntricos e abarcam o país inteiro até ao mar, ao Cais das Colunas e às suas ondas domesticadas de rio à portuguesa, senhor de mansas fúrias reflectindo a cor do céu e enodoado da sombra gordurosa das nuvens, meu remorso chama-lhe o poeta, meu remorso de todos nós.

1 Este hotel cardoseano exibe uma geometria vertical em que participam os arquétipos bachelardianos: o ponto cimeiro (o terraço, sítio interdito que serve de esconderijo, de evasão ao narrador) contrasta com os andares inferiores onde se encontra, em primeiro lugar, a sala de estar com o restaurante, um verdadeiro caos de uma multidão disforme à espera do prato do dia. É aqui que germinam as ideias subversivas, e as pessoas, sempre expostas aos olhares dos outros, comungam fraternalmente um ódio à metrópole que os não pode ou não quer aceitar. Metidos aos três ou quatro em quartos duplos, com saída para os corredores sempre a abarrotar de gente, os hóspedes ficam destituídos de privacidade, afundando-se na alienação e violência irracional. É nesta perspetiva que o hotel poderia assemelhar-se ao hospital, metonimicamente anunciado pelos "demónios" (os ataques nervosos) da mãe do narrador.

2 Cronologicamente, a história de Eva Lopo, que vem a Moçambique para se juntar ao seu noivo, entretanto profundamente alterado e reduzido a uma pobre cópia do seu capitão, passa-se nos últimos anos do conflito armado, já saturado do absurdo e do sem-sentido da presença portuguesa em África. Este romance coincide com a narrativa cardoseana no retrato do hotel como de uma casa transitória, totalmente isolada, paralisada, opressiva, asfixiante, cheia de intrigas, boatos e relações distorcidas. 
Muros concêntricos, repetiu ele, labirinto de casas e de ruas, descida íngreme e atrapalhada de mulher de saltos altos para a amplidão horizontal da barra, muros tão concêntricos que nunca se parte de facto, antes se criam raízes de crochet na alcatifa do sobrado, Creta de azulejos habitada de papagaios de janela e chineses de gravatas, bustos de regicidas heróicos, pombos gordos e gatos capados, onde o lirismo se mascara de canário em gaiola de cana soltando os trinadinhos de sonetos domésticos. (p. 43-44)

A heterotopia do hospital/hotel pode, assim, representar um huis clos português do fim do império, cujo declínio é n’As Naus e n'O Retorno simbolizado pelos contentores, depositados na margem do rio, nos quais apodrece seja o lixo, seja aquilo que foi trazido das colónias.

Por extensão, a própria cidade, a Lisboa pós-colonial, também se apresenta como uma heterotopia, como o espaço fechado, doente, carcomido, cujo corpo em supuração precisa de purificar-se em vias de uma regeneração. Não faltam as descrições que traduzem a decadência urbana, roçando o aspeto moribundo ("A avenida Almirante Reis [...] trotava na direcção do Tejo entre duas gengivas de prédios cariados", p. 84, "Se calhar é isto a vida, pensou o médico saltando um cesto de crisântemos para alcançar o carro afogado em corolas como um cadáver de comendador”, p. 83). As metáforas da decadência prenunciam a imagem da cidade-sepulcro ("cidade morta, pensou o médico, cidade morta em urna de azulejos a esperar sem esperança quem não virá mais”, p. 102), essa que será reiterada no romance Os Cus de Judas. Neste sentido, na perspetiva do personagem-narrador, a cidade corresponde a um espaço infernal, domínio da morte e alienação mental. Plasma-se como a cidade deserta, sem alegria nem prazer da vida, para todos os que como o psiquiatra passaram pelo inferno bélico, ou pelo inferno da deslocação e perda das suas raízes. Assim, o psiquiatra funciona como vítima da crise social e existencial, manifestada pela errância através da capital portuguesa. De acordo com Eunice Cabral, a perspetiva do protagonista é "um olhar que vê a cidade como 'outra', encontrando-se distanciado deste espaço em termos emocionais" (Cabral 2008: 266). O sentimento de perda e a completa desorientação mostram-se através das suas obsessões, como é por exemplo a ida regular à Rocha do Conde de Óbidos, o ponto final das suas peregrinações pela cidade, que é na verdade o ponto inicial do seu calvário, aquando da partida para África. Deste ponto de vista, o aspeto da cidade funde-se perfeitamente com o espírito do sujeito, com o seu sentir:

Eu sou um homem de uma certa idade, citou ele em voz alta como sempre lhe acontecia quando Lisboa, num gesto meditativo de lagosta de viveiro, lhe apertava as pinças em torno dos tendões do pescoço, e casas, árvores, praças e ruas penetravam tumultuosamente na sua cabeça à moda de um quadro de Soutine dançando um charleston carnívoro e frenético. (p. 69)

Esta imagem é, de facto, a de uma cidade asfixiante. Há que porém ver que o narrador-personagem, embora magoado, consegue recriar também as imagens de uma ternura inesperada, à laia de um Cesário Verde, a figura tutelar na mitologia lisboeta e, ao mesmo tempo, a figura acarinhada pelo narrador-personagem. Através de imagens tiritantes de emoção, o narradorpersonagem recria o topos clássico da cidade-amante, a qual já não adquire os atributos vigentes nos Oitocentos (perigosamente sedutora que leva à perdição e causa a desilusão), mas 
exprime o caráter instável e incaptável da cidade, perseguida pelo protagonista na tentativa de a (re)conhecer:

Esta cidade que era a sua oferecia-lhe sempre, através das suas avenidas e das suas praças, o rosto infinitamente variável de uma amante caprichosa que as árvores escureciam do cone de sombra dos remorsos melancólicos, e acontecia-lhe tropeçar nos Neptunos dos lagos como um bêbedo se encontra, ao sair de um candeeiro, com o queixo feroz de um polícia sem humor, culturalmente alimentado pelos erros de gramática do cabo da esquadra. (p. 81)

Com esta imagem poético-melancólica passemos agora à vertente da cidade imaginária, ao espaço da memória e, simultaneamente, ao espaço do mito.

\section{Cidade imaginária}

Ao falar sobre a poética da cidade na ficção pós-moderna, Maria Alzira Seixo (1998: 166) afirma:

A cidade deixa de ser uma paragem no percurso do herói, uma "estação" no seu trânsito determinado pelas circunstâncias do acontecer efabulativo, para ser ela também um local de deslocação, de viagem, eventualmente de perda ou de encontro (como acontece em romances de Vergílio Ferreira ou de Augusto Abelaira, como acontece também em Thomas Bernhard ou Jean Echenoz), configurando assim uma poética do romance em termos que a crítica actual não pode ignorar.

Efetivamente, a errância do psiquiatra, longe do encanto do flâneur baudelaireano, traduz o esforço de protagonista em reaprender a cidade e, através dela, em se reconhecer a si próprio. $\mathrm{O}$ aspeto desta cidade transita entre o solar e o sombrio, modificando-se também em relação à hora do dia e da noite. Mas é especialmente a deambulação noturna pela cidade que interessa aqui e que, segundo Pierre Sansot, leva ao conhecimento de si (1971: 155). Tal deambulação noturna, como aliás qualquer peregrinação, representa também uma demanda mítica, em termos de uma aventura cavaleiresca, constituindo-se duplamente como uma viagem no espaço (através de referências aos lugares extraliterários) e, simultaneamente, como uma viagem às profundezas do eu:

De tout temps, les pèlerinages et les odyssées sont apparus comme des explorations intérieures. Un tel privilège ne devait pas nous surprendre à l'horizon d'une pensée mythique ou religieuse. Le voyage s'effectuait à travers des itinéraires surchargés de significations l'initié refaisait, sur un mode symbolique, les gestes du héros. (Sansot 1971: 155)

Várias vezes o protagonista se refere ao seu inferno interior, à uma descida ao "fundo do fundo dos fundos" (p. 63), procurando nesse labirinto de emoções contraditórias um fio de Ariadne que lhe escapa constantemente. É na verdade o sentimento da perda (de si, da mulher, da cidade) que faz o protagonista deambular pelo espaço crepuscular e noturno. Ao mesmo 
tempo, o espaço da memória é dominado pelas lembranças da guerra em Angola, que veiculam a imagética da morte e do lúgubre.

A viagem do psiquiatra desenha-se num arco: do hospital, passando por um rol de vários lugares com vontade de adiar o regresso a casa, chega finalmente ao seu apartamento no Estoril. Um pouco à maneira de James Joyce, porém mais subtil e ironicamente, o protagonista reitera o mito de Ulisses, da sua viagem de regresso de Tróia para Ítaca, durante a qual tem de enfrentar imensos perigos para provar a sua qualidade de herói. ${ }^{3}$ A versão (cripto)mítica, apresentada no romance antuniano, é, no entanto, burlesca e irreverente. É uma versão carnavalizada tanto do mito clássico, como de suas reescritas modernas.

Assim, hipoteticamente, o hospital poderia representar o lugar de batalha, a Tróia da morte e alienação, o consultório do dentista com o som da broca ameaçadora poderia ser a cova do Polifemo, o Casino a ilha de Circe, os semas da morte, dispersos no romance, aludiriam à descida ao reino de Hades e as mulheres dos bares às sereias. A mulher, na verdade, aciona a problemática do Outro, legível no motivo da mulher em geral e, especialmente, na mulher do protagonista, da qual este se divorciou apesar de nutrir por ela amor e apesar de ela significar para ele um objeto erótico por excelência. $\mathrm{O}$ regresso a casa seria assim um cúmulo de auto-ironia: o psiquiatra afinal regressa não para se reencontrar com a mulher, tantas vezes mencionada, desejada e idolatrada no texto, mas para passar uma noite insignificante com uma mulher igualmente insignificante e desconhecida. Um outro momento que subverte, carnavalizando, a aventura de Ulisses relaciona-se com o motivo do encontro do pai com a sua prole. Ao contrário de Ulisses que, na epopeia, acaba por se encontrar tanto com a mulher, como com o filho, o psiquiatra sofre um fracasso burlesco, sendo considerado um perverso ao espiar as suas filhas à saída da escola. Mas apesar disso, o jogo dos vetores espaciais (após as sucessivas descidas há uma subida para o apartamento) aponta para uma hipótese de ascensão, quiçá, uma esperança em reganhar o espaço da paz e liberdade.

Esta releitura do mito, por conseguinte, insere-se numa linha singular da ficção portuguesa pós-moderna, essa que pretende revisitar os textos/mitos fundadores da cultura ocidental e portuguesa a fim de reconstruir, problematizando, o imaginário coletivo. Recentemente, como recorda Annabela Rita (2014: 248), este trabalho de reescrita foi empreendido por Teolinda Gersão em A Cidade de Ulisses (2011) e por Gonçalo M. Tavares em Viagem à Índia (2010). Conforme Annabela Rita (2014: 287), a cidade de Lisboa é, para estes dois autores, o lugar onde estes se "encontram e se desencontram operaticamente através dos fantasmas do nosso imaginário colectivo nacional e do das suas ficções”. Por tradição, o mito de Ulisses faz parte da olisipografia e, atualizando a mitologia marítima, acentua também o imaginário pós-colonial. Assim, o protagonista qual um navegador empreende uma nova aventura de (re)descoberta das terras e gentes:

Girando o volante, para um e outro lado, como uma roda de leme, furtou-se aos hipopótamos adormecidos das stations a erguerem do rio do asfalto os olhos preguiçosos dos faróis, mamíferos tripulados por caixeiros-viajantes loquazes que percorriam a província em safaris em que as aldeias indígenas cediam lugar a coretos afligidos por psoríases de ferrugem. (p. 69-70)

3 Esta leitura inspira-se na interpretação do mito de Ulisses no romance de James Joyce, feita por Meletinskij (1989: 307-348). 
De mesma forma, no espaço são introduzidos os atributos marítimos ou, pelo menos, os elementos espaciais apontam para o mar como se indicassem um rumo a seguir ("Todas as estátuas apontavam o dedo na direcção do mar, convidando à Índia ou a um suicídio discreto," p. 81, "O edifício maciço do Arsenal enverdecia de musgos marinhos, saudoso de impossíveis naufrágios.” p. 86). O tom melancólico deste tipo de imagens talvez denuncie o facto de que a partir de agora (se não teria sido sempre assim), a única aventura possível é só aquela sonhada e imaginada. ${ }^{4}$

Por último, a vertente da cidade imaginária é moldeada, para além do mito, pelo seu caráter mestiço, pela inclusão de vários discursos, referências aos símbolos culturais ou alusões às ícones urbanas, como se a cidade fosse um palimpsesto sempre reelaborado e reescrito. Deste modo, o texto, veiculando uma interrogação sobre Lisboa como cruzamento de vozes do passado, da memória individual e coletiva, proporciona uma interação e confrontação entre o indivíduo e a cidade. Tal cruzamento de discursos e perspetivas reforça o dinamismo da cidade, aniquilando o estatismo da cidade morta. Na rede de um, assim criado, arquitexto ${ }^{5}$ urbano entram, por exemplo, as citações de vários poetas, escritores, artistas e músicos como Paul Simon (p. 94-95), Sophia de Mello Breyner Andresen (p. 86), Dylan Thomas (p. 137-138), F. Scott Fitzgerald (p. 152) ou Fernando Pessoa/Álvaro de Campos (p. 125). Tais referências aludem, entre outros, ao caráter da cidade militante (Sophia), ao mistério da noite na cidade/no interior (Thomas, Fitzgerald, Sue etc.) ou à procura de uma felicidade humilde (Álvaro de Campos). Juntem-se a estes e outros discursos literários também os discursos publicitários, ideológicos (p. ex., o cartaz anarquista, p. 101), às vezes carnavalizados (p. ex. a explanação sobre as classes das mulheres, p. 78) e outros, cuja enumeração está fora do alcance deste ensaio.

Por outro lado, convém relembrar o autor já aqui mencionado, Cesário Verde, cuja sombra se projeta no romance antuniano, sem que este fique prisioneiro daquele. Numa passagem, o narrador refere-se explicitamente ao poema "O Sentimento dum Ocidental" (1880), no qual, segundo Manuel Gusmão (2010: 199), Cesário inventou "para a poesia em português a mais elaborada configuração do topos literário da cidade moderna, mercantil e industrial”':

Ligou o motor para se evadir da sua ilha de pétalas meladas, da qual pulou como um golfinho de um lago num soluço de bielas, e desceu para o Martim Moniz espalhando caules, idêntico à Vénus de Botticelli redesenhada por Cesário Verde: O Sentimento Dum Ocidental era um pouco a sua roupa interior, ceroulas de alexandrinos nunca despidas, mesmo para os minutos ardentes de uma relação furtiva. (p. 84)

4 Repare-se, a propósito, que a imagética semelhante é delineada, entre outros, nos romances O Homem Suspenso (1996) de João de Melo e Manual de Pintura e Caligrafia (1977) de José Saramago. Nestes romances, o protagonista que é igualmente um homem preso na teia conflituosa da relação com a mulher, empreende também uma viagem noturna de carro pela cidade, revisitando alguns lugares centrais da mitologia pessoal e coletiva e, simultaneamente, refletindo sobre a sua condição humana.

5 O termo retirado dos ensaios de Hodrová 2006.

6 Para além de outras, muito interessantes explanações acerca da poesia de Cesário Verde, Gusmão refere-se também ao poema "Zone" de Apollinaire que, embora escrito muito para além do tempo de Cesário, constitui um texto literário com o qual o poema cesariano se possa cotejar. De facto, existe um paralelo entre o poema de Apollinaire e o romance antuniano: nos dois casos, a deambulação começa de manhã e acaba ao alvorecer do dia seguinte (2010: 203-205). 
A sequência narrativa, aberta por esta referência, fornece um subtil e talvez inconsciente diálogo entre o hipotexto cesariano e o hipertexto antuniano. Decreve-se o percurso do narrador ao longo da avenida Almirante Reis e através de ruas transversais em direção do Tejo, durante o qual o narrador nota a atmosfera (a avenida "eternamente cinzenta, pluviosa e triste", p. 84), os sintomas da decadência urbana ("gengivas de prédios cariados", p. 84), bem como os lugares de convivência social (cafés, cabeleireiros, lojas, cervejarias). O cenário observado proporcionalhe, também, um mergulho nas lembranças do passado (a carvoaria da infância do narrador faz lembrar "os carvoeiros que aparecem ao fundo dumas minas" de Cesário, p. 83). Ao lado destes motivos (percurso do sujeito pelas ruas até ao cais, sensibilidade à atmosfera, notação da decadência e referência aos sítios sociais), verificáveis na leitura das primeiras estrofes de "O Sentimento dum Ocidental", convém referir também certa ternura para com os “traseiros de prédios fuliginosos de que ele gostava, com as marquises salientes como verrugas de ninhos precários em que se adivinhavam as tábuas de passar a ferro e melancolias domésticas" (p. 110) que invocam, agora conscientemente, ${ }^{7}$ as imagens cesarianas de pobres engomadeiras lisboetas.

\section{Um navegador solitário na noite lisboeta: metamorfoses do espaço urbano}

Após o percurso pela estreia romanesca de Lobo Antunes podemos verificar que o autor trabalha conscientemente com o topos da cidade de Lisboa, enriquecendo-o pelas ressonâncias míticas e intertextuais. No romance criam-se várias imagens urbanas que se estabelecem seja na vertente do real, seja na vertente do imaginado. Assim, o sujeito narrador faz parte desse grande universo urbano em que o mítico transparece no quotidiano, sem no entanto abstrair dos aspetos da contemporaneidade, geradora de uma visão magoada e pessimista.

O decadente não funciona só como atributo da cidade pós-colonial, em fase da procura de nova identidade, mas torna-se também o atributo do narrador-personagem, em estado de perda e de uma nova procura de si e do Outro. O elo entre a cidade e o narrador é deveras forte. Este parece que seja tão visceralmente ligado à cidade que só através dela, palpando-a e reconhecendo-a nas suas misérias, possa empreender uma viagem exorcista ao âmago das suas próprias feridas.

O topos da viagem, recuperado a nível intimista e existencial, constitui também o cerne do imaginário urbano pós-colonial. O narrador transforma-se num navegador desiludido à procura de novas descobertas, puramente imaginárias, desconstruindo a epopeia marítima através da ironia e do burlesco. A Lisboa pós-colonial, enriquecida pela imagística africanista (metáforas de hipopótamos, safaris etc.) adquire caraterísticas de uma cidade híbrida em que desaparecem os limites entre as categorias do próprio e do outro, neste caso ultramarino, para se tornar

7 A seguir a esta citação o narrador invoca o nome do poeta, refere-se ao seu busto e nota mais um quadro lisboeta, ao qual Cesário, pela sua simpatia para com os pobres, sem dúvida não teria ficado indiferente ("Amigo Cesário, disse o psiquiatra com ternura, vi a semana passada qualquer coisa que te traria à boca alexandrinos de alegria: procurava eu sítio onde jantar e passando rente ao teu busto iluminado na berma de relva estefânica em que o puseram, dei com uma velha de preto sentada no degrau da estátua com uma alcofa aos pés, e compreendi então a diferença que vai de ti ao Eça e que é a mesma que separa o abraço a uma virgem de pedra da vizinhança de uma criatura viva, arrancada à solidez de carne dos teus versos", p. 110-111). 
num palco de uma nova aventura às avessas. Tal configuração urbana, veiculada pelo topos da viagem (real e imaginária), é também essencialmente ligada à questão da identidade coletiva, à reflexão sobre o destino português que deve ser perspetivado dentro de um contexto literário mais vasto. Num ensaio publicado em 1986, Eduardo Lourenço (1986) invoca propriamente a figura de Fernão Mendes Pinto, contrapondo-o a Camões, como símbolo de uma nova aventura cultural portuguesa que se desvia da "aventura imperial". Neste sentido, a viagem noturna pela cidade, empreendida pelo psiquiatra antuniano, pode ser também lida, a nível simbólico, como uma viagem picaresca que ressuscita o mito de Mendes Pinto. Aliás, duas décadas após a publicação de Memória de Elefante, em 1996, João de Melo recriará este mesmo mito na figura dum outro navegador solitário, o narrador do romance O Homem Suspenso. Só com a diferença de que nos anos noventa a discussão já não se centra tanto na relação de Portugal ao Ultramar, mas na relação à União Europeia, e, consequentemente, na ameaça de a cidade de Lisboa se tornar numa cidade esvaziada, em "sítio nenhum".

Mas apesar de tudo isso, não é somente nos aspetos do urbano degradado, vazio ou híbrido que o narrador procura um certo tipo de identificação. Há recantos urbanos que o enchem de ternura. E há sobretudo os motivos em diálogo com o imaginário cesariano que já, quase imperceptivelmente, transmitem esse tipo de mitificação de Lisboa que viria a ser uma das mais fortes linhas temáticas nos romances e especialmente nas crónicas escritas por Lobo Antunes posteriormente. Nesta contaminação poética, também, o noturno lisboeta, materializado numa viagem de carro pela cidade, poderá ser lido como uma passagem catalética parecida à de Cesário Verde, que é afinal rematada por uma promessa da alba.

\section{Referências bibliográficas}

Antunes, A. L. (2004). Memória de Elefante. 22. ${ }^{a}$ ed. Lisboa: Dom Quixote.

Benjamin, W. (1979). Dílo a jeho zdroj. Praha: Odeon.

Cabral, E. (2008).Verbete “Lisboa” In Seixo, Maria Alzira (dir.). Dicionário da Obra de António Lobo Antunes. Vol. I. Lisboa: Imprensa Nacional-Casa da Moeda.

Cardoso, D. M. (2012). O Retorno. Lisboa: Tinta-da-China.

Foucault, M. (2003). Myšlení vnějšku. Trad. Č. Pelikán. Praga: Herrmann \& synové.

Gusmão, M. (2010). Cesário Verde: o 'cartógrafo' e a temporalização dos mapas. In Tatuagem \& Palimpsesto da poesia em alguns poetas e poemas. Lisboa: Assírio \& Alvim.

Hodrová, D. (2006) Citlivé město (eseje z mytopoetiky). Praha: Akropolis.

Jorge, L. (1988). A Costa dos Murmúrios. Lisboa: Dom Quixote.

Lourenço, E. (1986). Da contra-epopeia à não-epopeia: de Fernão Mendes Pinto a Ricardo Reis. Revista Crítica de Ciências Sociais no 18/19/20.

Meletinskij, J. M. (1989). Poetika mýtu. Trad. J. Žák. Praha: Odeon.

Melo, J. de. (1996). O Homem Suspenso. Lisboa: Publicações Dom Quixote.

8 Melo (1996: 66); no romance antuniano fala-se também de uma "certeza de vazio" (p. 75) ou de uma "cidade deserta" (p. 75). 
Reis, C. (2012). Lisboa como paisagem. A Cidade segundo Fradique Mendes. Colóquio-Letras, $n^{\circ}$ 179, Janeiro/Abril.

Rita, A. (2014). LuzǼSombras do Cânone Literário. Lisboa: Esfera do Caos.

Sansot, P. (1971). Poétique de la ville. Paris: Klincksieck.

Seixo, M. A. (1998). Poética da cidade na ficção europeia do Pós-modernismo. In Poéticas da viagem na literatura. Lisboa: Edições Cosmos.

Verde, C. (s/d). Noite fechada. In O Livro de Cesário Verde. Lisboa: Biblioteca Ulisseia. 
